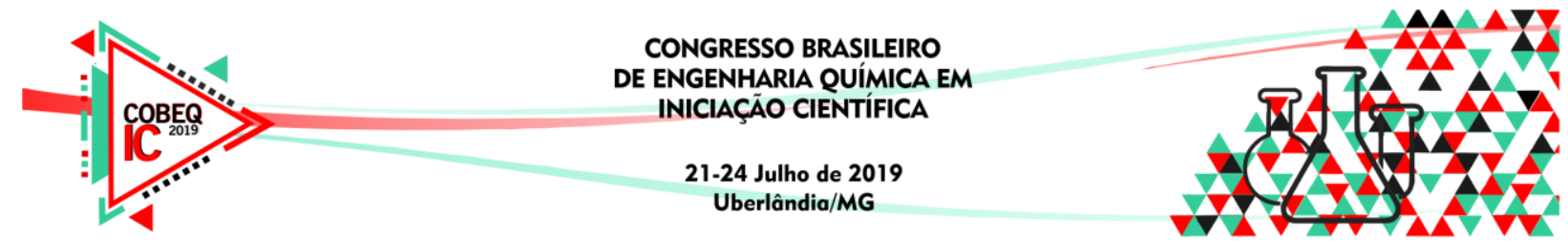

\title{
ESTUDO EXPERIMENTAL DA TRANSIÇÃO DOS REGIMES DE ESCOAMENTO EM UM DISCO ROTATÓRIO
}

\author{
POTENZA, F. ${ }^{1}$, I.A. MORAIS ${ }^{1}$, R. M. LIMA ${ }^{1}$, C. R. DUARTE ${ }^{1}$, M.A.S.BARROZO ${ }^{1}$ \\ ${ }^{1}$ Universidade Federal de Uberlândia, Faculdade de Engenharia Química \\ E-mail para contato: fer.potenza@hotmail.com
}

\begin{abstract}
RESUMO - Diante da grande importância dos discos rotatórios em processos industriais como a granulação e dos poucos dados presentes na literatura sobre o equipamento, este trabalho tem como objetivo a compreensão do comportamento de partículas no interior de um disco rotatório. Por meio de dados coletados experimentalmente, estudou-se a relação existente entre a massa máxima dentro do disco, o ângulo de inclinação e a velocidade de rotação. Assim, ao final da análise, percebe-se que, enquanto o aumento no ângulo de inclinação resultou em uma redução de partículas, o aumento na velocidade diminuiu a intensidade com que as partículas eram expelidas do equipamento. Dessa forma, apresentaram uma influência oposta na quantidade de massa retida no disco rotatório, influenciando na mudança dos regimes de escoamento, já que o aumento da massa e a diminuição da inclinação atuaram antecipando os regimes de escoamento, alcançando a centrifugação mais rapidamente.
\end{abstract}

\section{INTRODUÇÃO}

O processo de granulação tem como objetivo a conversão de pós finos em materiais granulares, alcançando um aumento no tamanho das partículas devido à colisão que estas sofrem no movimento de rolamento do dispositivo utilizado. Além disso, o material terá propriedades físicas controladas, melhor manuseio, dureza e melhoria na qualidade do produto (Litster e Ennis, 2004; Capes, 1980).

Nesse processo, o princípio básico no início é a adição de um líquido aglutinante que causará o aglomeramento das partículas em um único núcleo granular. Por meio da rotação em torno do seu próprio eixo, a agitação das partículas e as colisões entre os grânulos e o equipamento granulador promoverão a granulação (Capes, 1980).

Dentre os equipamentos que envolvem escoamentos granulares, destaca-se o tambor e o disco rotatório, largamente utilizados em processos de granulação (Capes, 1980). A aplicação de ambos equipamentos deve-se à simplicidade em seus design e por possuírem a capacidade de operar com partículas contendo larga faixa de distribuição granulométrica. $O$ tambor consiste em uma estrutura cilíndrica horizontal que gira em torno do seu próprio eixo enquanto o disco possui uma inclinação variando de $0-90^{\circ}$, conforme apresentado na Figura 1. Apesar de serem equipamentos simples, o comportamento granular em seu interior é relativamente complexo e sua eficiência é influenciada pelo movimento de seu leito, o qual 


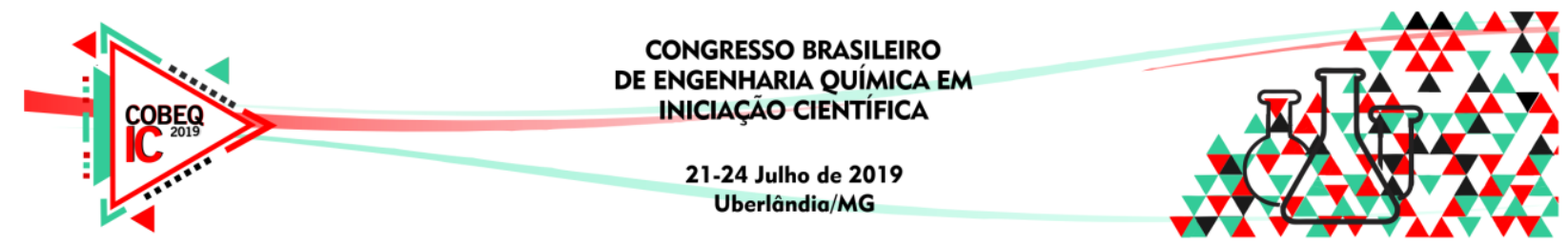

está relacionado com as taxas de transferência de massa, energia e quantidade de movimento envolvidas em cada regime de escoamento do material (Santos et al., 2013).

Figura 1: Diagrama esquemático do disco rotatório (CHADWICK, 2005).
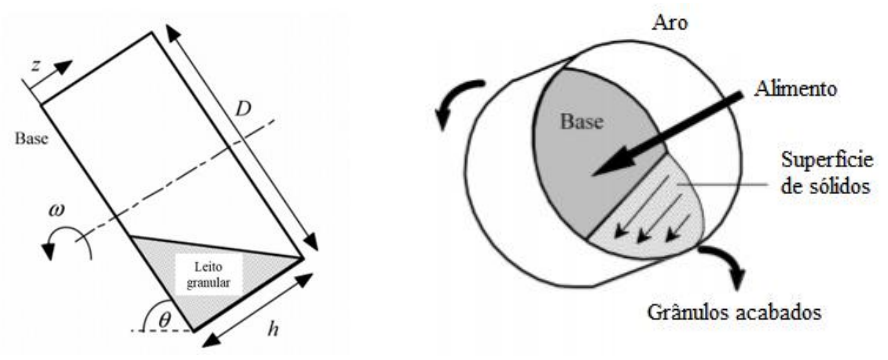

Segundo Mellmann (2001), os parâmetros de projetos e as condições operacionais utilizadas são extremamente importantes para a compreensão do comportamento das partículas dentro dos tambores rotatórios. Internamente, o leito pode apresentar os diferentes regimes de escoamento: deslizamento, avalanche, rolamento, cascateamento, catarateamento e centrifugação. Estes regimes também podem ser encontrados no disco rotatório.

Chadwick e Bridgwater (1997) apresentaram o efeito das propriedades do disco e do material no fluxo do leito granular e na necessidade energética. Os autores demonstraram que em velocidades muito baixas de rotação do prato, a superfície da cama é plana e, à medida que a velocidade de rotação aumenta, o material forma um perfil parecido com um "rim". Em altas velocidades de rotação, atinge-se os regimes de cascateamento, onde as partículas são lançadas no interior do disco rotatório, como pode ser observado na Figura 2.

Figura 2: padrões de fluxo e regimes típicos encontrados no disco rotatório (Chadwick e Bridgwater, 1997).

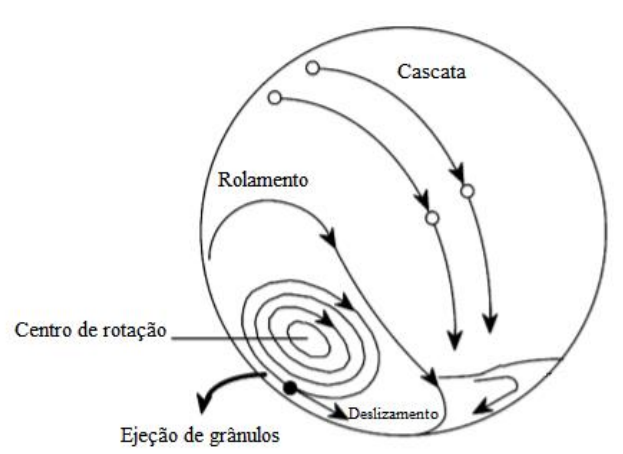

Apesar de possuírem comportamentos e aplicações semelhantes, os tambores rotatórios apresentam uma literatura vasta sobre a dinâmica de partículas em seu interior (Mellmann, 2001; Santos et al., 2013), enquanto o mesmo não pode ser encontrado para os discos rotatórios. Dessa forma, o objetivo deste trabalho é estudar os aspectos do fluxo de partículas dentro do disco rotatório, o qual possui as mesmas características e regimes de escoamento do tambor; variando os ângulos de inclinação e o grau de preenchimento. 


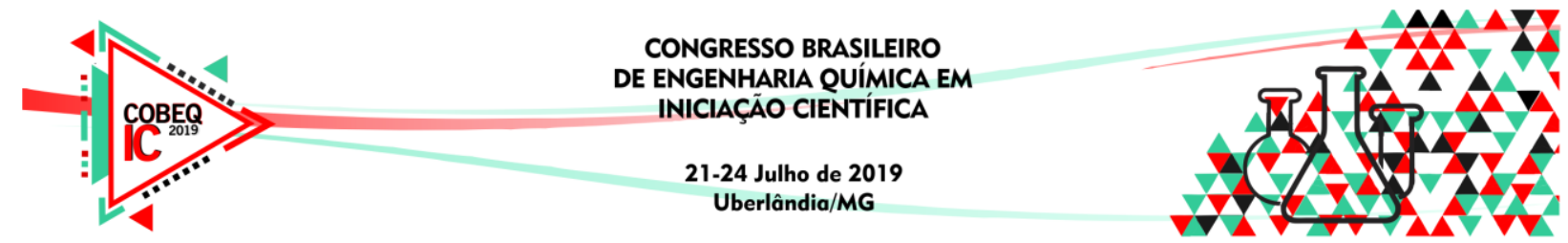

\section{METODOLOGIA}

\subsection{Material granular e disco rotatório}

A medição experimental foi realizada utilizando partículas de soja de diâmetro $0,006 \mathrm{~m}$, densidade $1190 \mathrm{~kg} / \mathrm{m}^{3}$ e porosidade 0,37 .

O disco rotatório utilizado apresenta um diâmetro de $0,35 \mathrm{~m}$ e $0,20 \mathrm{~m}$ de borda, fabricado em aço inox, o qual apresenta uma inclinação regulável variando de $0-75^{\circ}$ como apresentado na Figura 3. A velocidade de rotação do disco é controlada por um inversor de frequência e medida utilizando um tacômetro digital.

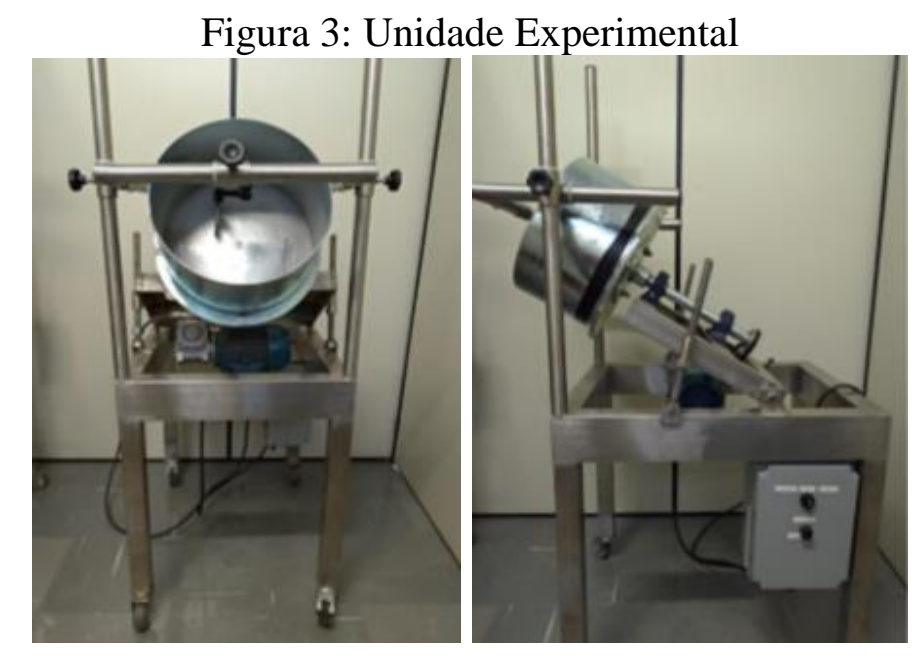

\subsection{Determinação da massa máxima}

Nesta etapa, utilizou-se o disco e a soja juntamente com uma balança e uma sacola para a captação das partículas. Como o disco possui uma abertura, existe um limite de massa que pode ser colocado no equipamento. Para determinar esse limite, a soja foi adicionada nos ângulos de inclinação (A.I.) de 30, 40, 45, 50, 60 e $70^{\circ}$ e nas velocidades de rotação (V.R.) de $5,10,20,30$ e $50 \mathrm{rpm}$.

Ao decorrer da rotação, partículas foram lançadas para fora do disco e recolhidas pela sacola. Após a estabilização da rotação e o com o fim de partículas sendo arremessadas para fora do disco, o leito restante do disco foi retirado e pesado na balança, sendo essa a massa máxima restante na angulação e velocidade definidas. O processo foi realizado em triplicata.

\subsection{Determinação da mudança de regime}

Como já mencionado, no interior do disco, os regimes de escoamento variam em: deslizamento, avalanche, rolamento, cascateamento, catarateamento e centrifugação. Para determinar-se a transição desses regimes, foi necessário o uso de uma câmara de vídeo digital de alta velocidade da marca Fastec IL5 para ser analisado o comportamento das partículas. 


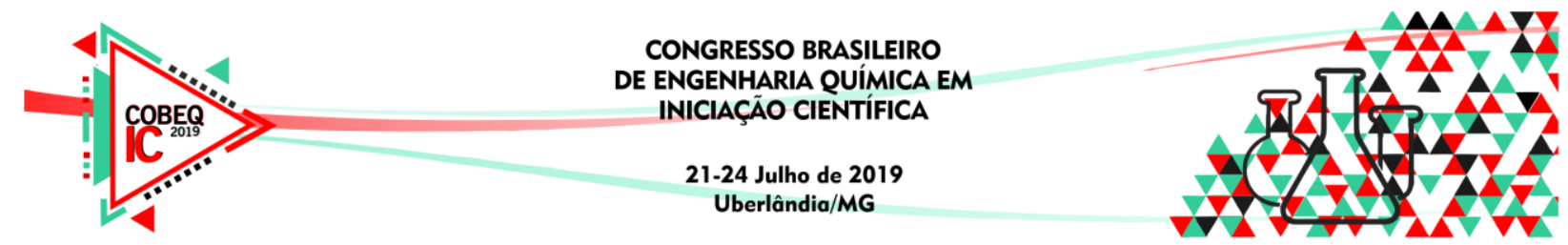

Com o auxílio de um medidor de ângulo digital a câmera foi colocada na mesma inclinação do disco rotatório, a fim de evitar efeitos de angulação na imagem.

Nesse processo, foi utilizado um grau de preenchimento de 10, 20 e $30 \%$ do disco rotatório, tendo com base na análise da menor massa encontrada do tópico anterior, a angulação em estudo foram de 40 e $50^{\circ}$. A velocidade foi aumentada de 5 em $5 \mathrm{rpm}$, iniciando de $10 \mathrm{rpm}$ até atingir o regime de centrifugação. As filmagens foram realizadas em cada intervalo de aumento de velocidade.

\section{RESULTADOS E DISCUSSÃO}

A Figura 1 apresenta os resultados da massa máxima encontrada para cada combinação de ângulo de inclinação (A. I.) e velocidade de rotação (V. R.).

Figura 4 - Massa máxima (kg) possível no disco rotatório.

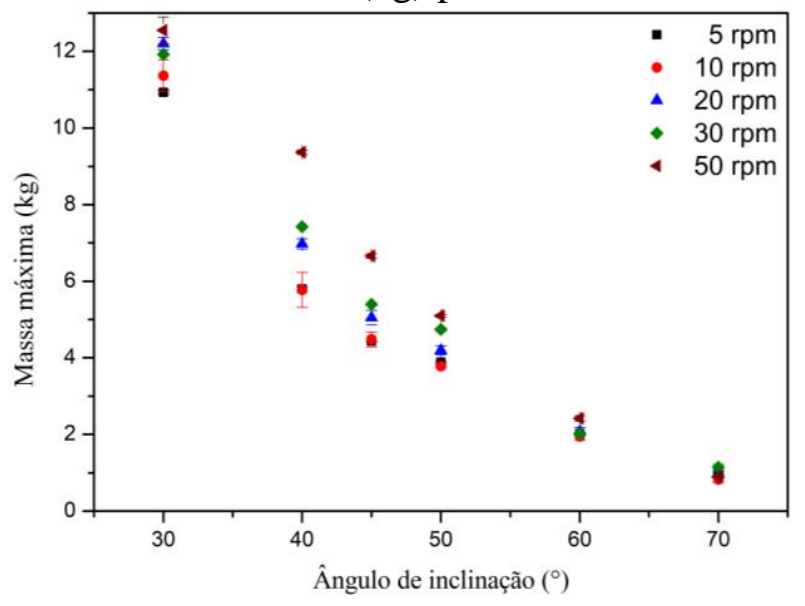

Analisando a figura percebe-se que o aumento da inclinação do disco rotatório acarretou na diminuição da massa enquanto o aumento da velocidade de rotação teve um comportamento contrário, retendo uma maior massa no interior do equipamento.

Destaca-se que o ângulo de inclinação apresentou uma maior influência na variação de massa do disco rotatório, quando comparado com a velocidade de rotação. A mudança de ângulo de $30^{\circ}$ para $60^{\circ}$ na velocidade de $5 \mathrm{rpm}$ resultou em uma diminuição de $81,5 \%$ de massa de soja, já para a velocidade de $50 \mathrm{rpm}$, para esses mesmos ângulos, a perda de partículas foi de $80,7 \%$. Realizando essa mesma análise para a velocidade de rotação, a mudança de velocidade de 5 a $50 \mathrm{rpm}$ para a inclinação de $30^{\circ}$ causou um aumento de $14,7 \%$ da massa, enquanto para $60^{\circ}$ esse aumento foi de $19,5 \%$.

Tendo agora como referência a quantidade máxima de soja que o disco suporta em cada ângulo/velocidade discutido anteriormente, foram determinados os graus de preenchimento de 10,20 e $30 \%$ para os ângulo de inclinação de 40 e $50^{\circ}$. A menor massa encontrada para cada um desses ângulos $(5,78$, e 3,78 respectivamente) foram adotadas como a massa limite e a partir delas o disco rotatório foi preenchido com 10, 20 e $30 \%$ de seu valor. 


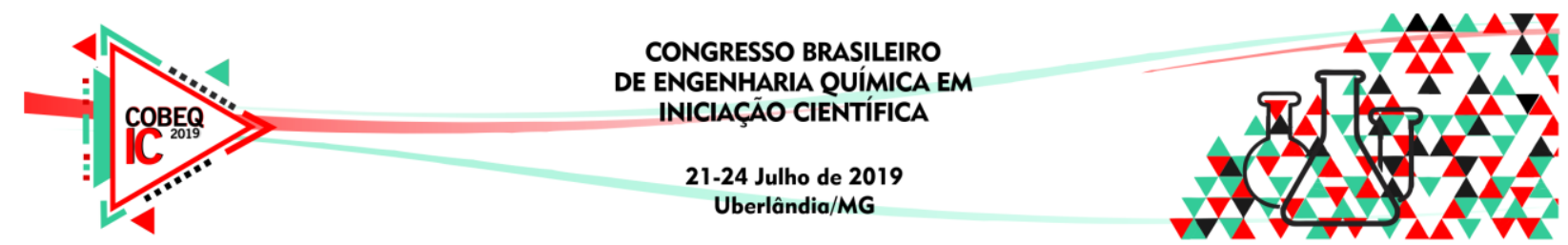

A influência do grau de preenchimento nos regimes de escoamento são apresentados na Figura 5. Foram selecionadas imagens nas velocidade de 10, 30, 50 e $80 \mathrm{rpm}$ a fim de ilustrar qualitativamente a variação da dinâmica de partículas devido ao aumento de massa.

Figura 5 - Influência do grau de preenchimento no escoamento de partículas no interior de um disco rotatório.

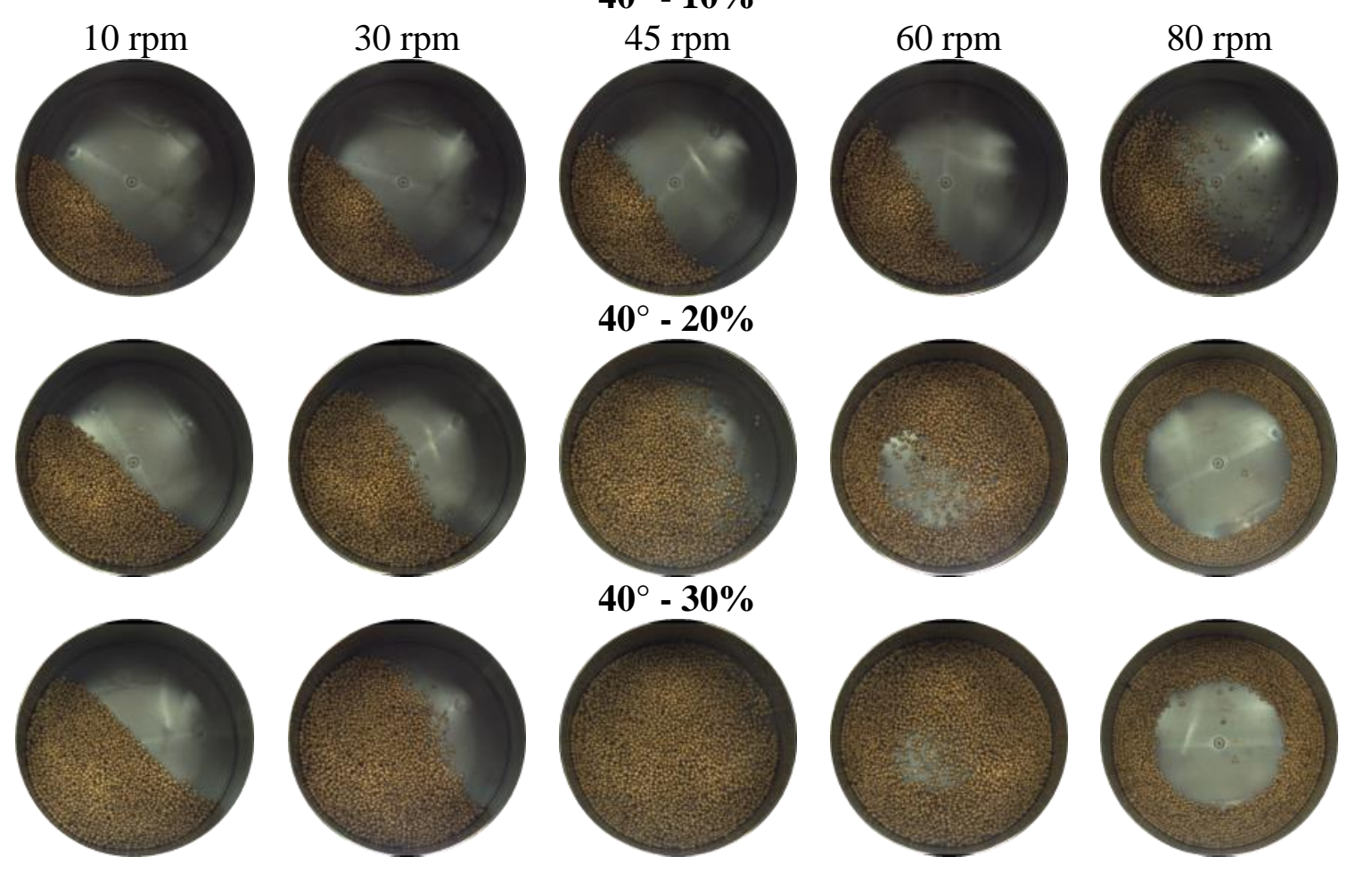

Note que quando se aumentou a massa teve um antecipação dos regimes de escoamento. Para a velocidade de $30 \mathrm{rpm}$ enquanto em $10 \%$ o regime ainda estava no rolamento para $20 \%$ e $30 \%$ as partículas começavam a desprender do leito granular, iniciando o catarateamento. Em $45 \mathrm{rpm}$, no menor grau de preenchimento o regime se encontra em cascateamento, sendo possível observar um leve formato de "S" no leito, na massa intermediária $(20 \%)$ o regime está no catarateamento, onde as partículas estão sendo arremessadas para o interior do disco e em 30\% nota-se que o regime está próximo de centrifugar, a borda está quase toda preenchida de soja. Santos et al. (2013) discutem que o regime de centrifugação inicia somente quando uma primeira camada de partículas aderem a parede do equipamento. Em $80 \mathrm{rpm}$ a centrifugação total é alcançada para as duas massas maiores.

A Figura 6 apresenta a influência da inclinação do disco rotatório no regimes de escoamento. É possível observar que a mudança de inclinação do disco também influenciou nos regimes de escoamento. Com o aumento da inclinação se faz necessário uma maior velocidade de rotação para alcançar os regimes, quando comparado com o ângulo de $40^{\circ}$. Percebe-se que em $40^{\circ}$ o processo de centrifugação começa a iniciar em torno da velocidade de $45 \mathrm{rpm}$ enquanto em $50^{\circ}$ o regime ainda está em cascateamento e só entrará em centrifugação com uma velocidade superior a de $80 \mathrm{rpm}$. 


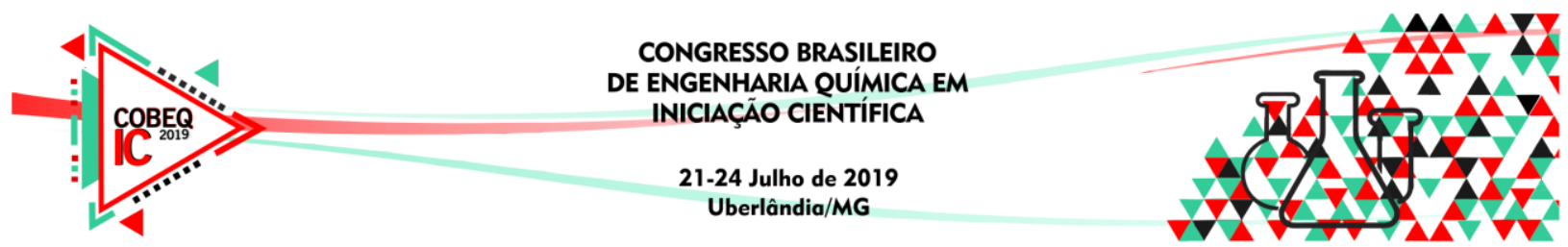

Figura 6 - Influência do ângulo de inclinação no escoamento de partículas no interior de um disco rotatório.

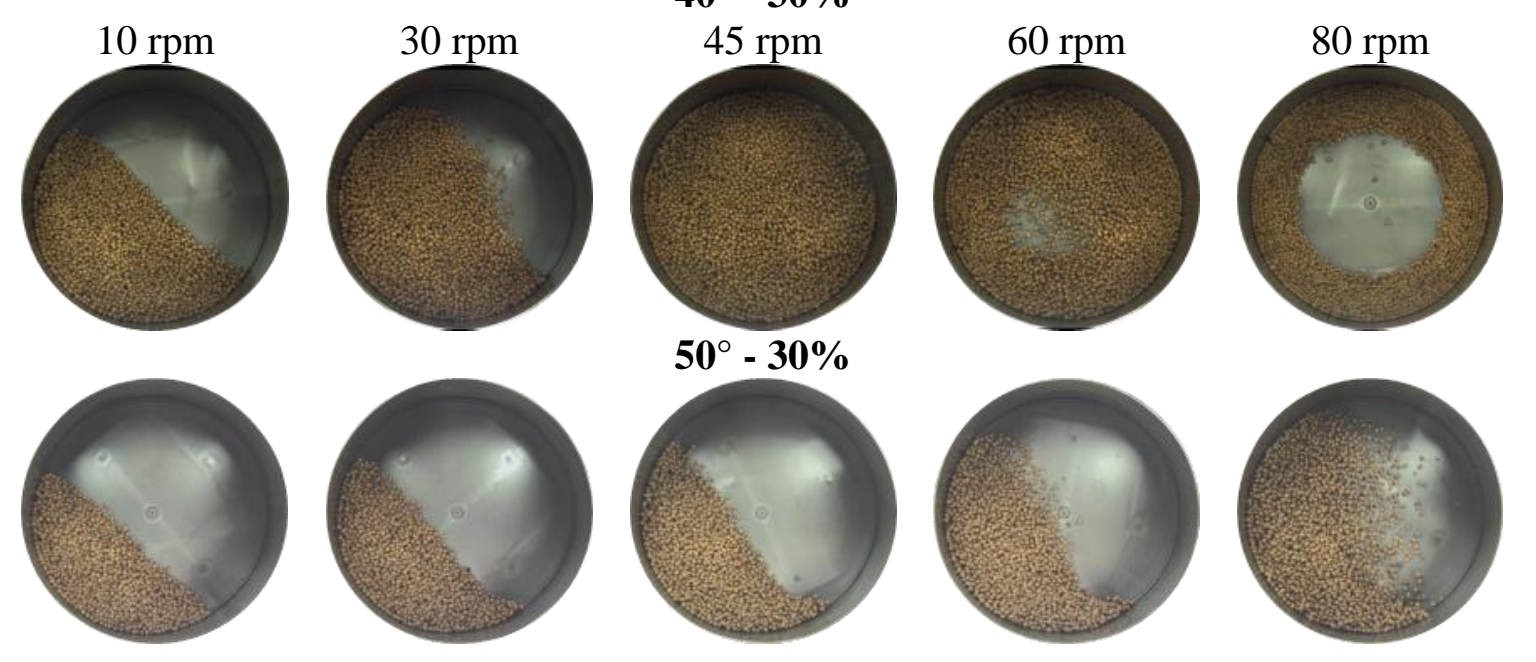

\section{CONCLUSÃO}

O ângulo de inclinação e a velocidade de rotação apresentaram uma influência oposta na quantidade de massa retida no disco rotatório. O aumento do ângulo resultou em uma redução de partículas enquanto o aumento da velocidade diminuiu a intensidade com que as partículas eram expelidas do equipamento. Destaca-se uma maior influência do ângulo da variação de massa quando comparado com a velocidade de rotação.

A análise qualitativa das imagens demonstrou que tanto o ângulo de inclinação quanto o grau de preenchimento influenciaram na dinâmica das partículas no disco rotatório. $\mathrm{O}$ aumento da massa e a diminuição da inclinação atuaram de forma a antecipar os regimes de escoamento, alcançando a centrifugação mais rapidamente.

\section{REFERÊNCIAS}

CAPES. C. E. Particle size enlargement. Elsevier Scientific Publishing Company, 1980.

CHADWICK, P. C.; BRIDGWATER, J. Solids flow in dish granulators. Chemical Engineering Science, v. 52, p. 2497-2509, 1997.

LITSTER, J.; ENNIS, B. The science and engineering of granulation processes. Springer Science, 2004.

MELLMANN, J. The transverse motion of solids in rotating cylinders-forms of motion and transition behavior. Powder Technology, v. 118, n. 3, p. 251-270, 2001.

SANTOS, D. A.; PETRI, I. J.; DUARTE, C. R.; BARROZO, M. A. S. Experimental and CFD study of the hydrodynamic behavior in a rotating drum. Powder Technology, v. 250, p. 52-62, 2013. 